\title{
Het gebruik van alternatieve financiële prestatie-indicatoren in persberichten
}

\section{Erika Marseille en Ruud Vergoossen}

SAMENVATTING Persberichten over de jaarresultaten van beursgenoteerde ondernemingen komen eerder uit dan de jaarrekening zelf en krijgen veel aandacht van de media. Dat laatste geldt ook voor de persberichten waarmee kwartaal- en halfjaarcijfers naar buiten worden gebracht. Het is daarom van groot belang dat deze persberichten eenduidige en betrouwbare informatie presenteren. Dit artikel doet verslag van een onderzoek naar het gebruik van alternatieve (niet-gedefinieerde) financiële prestatieindicatoren in de persberichten van 146 beursgenoteerde ondernemingen. Daaruit blijkt dat die veelvuldig en soms op misleidende wijze worden gebruikt. Zij hebben veelal een prominente plaats in het persbericht, terwijl een nadere toelichting of een aansluiting met gedefinieerde (winst)begrippen regelmatig ontbreekt. Ook valt er in de tijd gezien in de persberichten een weinig consistent gebruik van alternatieve financiële prestatie-indicatoren te constateren. Zolang het gebruik van alternatieve financiële prestatie-indicatoren niet goed is geregeld, doen beleggers er goed aan de nodige voorzichtigheid te betrachten bij het nemen van beslissingen op basis van in persberichten gepresenteerde financiële resultaten.

\section{Inleiding}

Iedere beursgenoteerde onderneming in Nederland brengt ten minste elk halfjaar een persbericht uit om

Drs. E.A. Marseille RA houdt toezicht op financiële verslaggeving bij de Autoriteit Financiële Markten.

Prof.dr. R.G.A. Vergoossen RA is voorzitter van het directoraat Vaktechniek van Ernst \& Young Accountants en als hoogleraar Internationale Externe Berichtgeving verbonden aan de Universiteit Maastricht. de financiële resultaten te presenteren. Bij het lezen van deze persberichten blijkt dat er weinig consistentie in het gebruik van financiële (winst)begrippen is en dat er verschillende maatstaven worden gehanteerd ten aanzien van financiële prestaties. Naast of in plaats van het begrip nettowinst (of -verlies), vermelden veel ondernemingen allerlei andere financiële prestatie-indicatoren, zoals EBITDA (earnings before interest taxes depreciation and amortization), EBITA en EBIT.

Ondernemingen zijn ten aanzien van de inhoud van persberichten niet gebonden aan regels. Ofschoon informatie in persberichten niet dient als vervanging voor de informatie in de wettelijk voorgeschreven jaarrekening, levert het gebruik van alternatieve en soms misleidende financiële prestatie-indicatoren verwarring op. Dit klemt omdat persberichten met een grotere regelmaat (kwartaal- en halfjaarcijfers) en - als het de jaarcijfers betreft - ruim vóór de openbaarmaking van de officiële jaarrekening naar buiten worden gebracht. De actualiteitswaarde van deze persberichten is daardoor hoger dan die van de jaarrekening ${ }^{1}$. Dit blijkt ook uit de publiciteit die persberichten genereren en de waarde die beleggingsanalisten daaraan hechten.

In dit artikel wordt verslag gedaan van een tweetal onderzoeken van de Autoriteit Financiële Markten (AFM) respectievelijk Ernst \& Young Accountants naar het gebruik van alternatieve financiële prestatieindicatoren in de persberichten van 146 beursgenoteerde ondernemingen ${ }^{2}$. Het artikel bevat een compilatie van de resultaten van beide onderzoeken. Omdat de onderzoeken complementair zijn, wordt hierna steeds gerefereerd aan 'het onderzoek'.

De volgende paragraaf beschrijft wat onder alternatieve financiële prestatie-indicatoren moet worden verstaan, waarna paragraaf 3 ingaat op de relevante wet- en regelgeving. Paragraaf 4 geeft het doel, de reikwijdte en de aanpak van het onderzoek weer. Para- 
graaf 5 bevat de analyse van het gebruik van alternatieve financiële prestatie-indicatoren. Daarbij wordt een onderscheid gemaakt tussen ondernemingen opgenomen in de AEX-index van Euronext Amsterdam en andere Nederlandse beursgenoteerde ondernemingen. In paragraaf 6 , ten slotte, volgen de conclusies.

\section{Definitie alternatieve financiële prestatie- indicatoren}

Een financiële prestatie-indicator kan worden omschreven als een maatstaf die inzicht beoogt te geven in de financiële prestatie van een onderneming. Het samenstel van financiële (winst)begrippen en maatstaven wordt in internationaal verband ook wel aangeduid als financial measures.

Relevante wet- en regelgeving die algemeen aanvaard is voor financiële verslaggeving wordt aangeduid met GAAP (generally accepted accounting principles). Een financiële prestatie-indicator die niet voldoet aan een (winst)begrip dat overeenkomt met GAAP, wordt aangeduid als alternatieve financiële prestatie-indicator; in de Amerikaanse regelgeving non-GAAP financial measure genoemd.

De definitie in Amerikaanse regelgeving voor alternatieve financiële prestatie-indicatoren luidt: 'a nonGAAP financial measure is a numerical measure of a company's historical or future financial performance, financial position or cash flows that:

- excludes amounts, or is subject to adjustments that have the effect of excluding amounts, that are included in the most directly comparable measure calculated and presented in accordance with GAAP in the statement of income, balance sheet or statement of cash flows (or equivalent statements) of the issuer; or

- includes amounts, or is subject to adjustments that have the effect of including amounts, that are excluded from the most directly comparable measure so calculated and presented' (SEC rule Section 401(b) of the Sarbanes-Oxley Act).'

Bovenstaande definitie houdt in dat alternatieve financiële prestatie-indicatoren anders zijn samengesteld dan de volgens GAAP gedefinieerde (winst)begrippen, waardoor posten buiten beschouwing zijn gebleven, of juist zijn opgenomen. Dit heeft tot gevolg dat ondernemingen allerlei bedragen of bewerkingen van bedragen kunnen verantwoorden die afwijken van de wet- en regelgeving voor de financiële verslaggeving. De Nederlandse wetgeving omvat het Besluit Modellen Jaarrekening (BMJ). Alle termen die in de modellen worden gebruikt, zijn financiële prestatieindicatoren die in Nederlandse GAAP zijn gedefi- nieerd. Alle andere termen zijn alternatieve financiële prestatie-indicatoren, behoudens twee uitzonderingen:

- 'bedrijfsresultaat' en 'operationeel resultaat'. Hoewel deze termen in het BMJ niet zijn gedefinieerd, zijn ze zozeer ingeburgerd, dat ze in dit onderzoek niet als alternatieve financiële prestatie-indicator zijn beschouwd;

- 'nettowinst' en 'nettoverlies'. Volgens het BMJ moet het 'resultaat na belastingen' worden gegeven, maar de vermelding 'nettowinst' of 'nettoverlies' geeft geen aanleiding tot verwarring en is daarom niet beschouwd als alternatieve financiële prestatie-indicator.

\section{Wet- en regelgeving}

Het veelvuldig gebruik van alternatieve financiële prestatie-indicatoren in Nederland heeft ertoe geleid dat de Raad voor de Jaarverslaggeving (RJ) hieraan in jaarrekeningen al enigszins paal en perk heeft gesteld. De RJ vindt het gebruik van EBITA en EBITDA in de winst- en verliesrekening onverenigbaar met artikel 6 lid $1 \mathrm{BMJ}$ en dientengevolge kunnen deze begrippen slechts worden gehanteerd in de toelichting bij de winst- en verliesrekening (RJ 270.709). In tegenstelling tot de officiële jaarrekening is het persbericht vormvrij. Wel heeft de AFM, beoogd toezichthouder op financiële verslaggeving, aanbevelingen gedaan over het gebruik van alternatieve financiële prestatie-indicatoren in de berichtgeving over financiële resultaten ${ }^{3}$. Hoewel het persbericht vormvrij is, bevat de Nederlandse wet (artikel 2:395 lid 2 BW) een inhoudelijke bepaling over de accountantsverklaring die bij de onderliggende jaarrekening is afgegeven. Artikel 2: 395 lid 2 BW schrijft voor dat bij de publicatie van een beknopte jaarrekening of van een gedeelte van de jaarrekening duidelijkheid moet worden verschaft over de status van deze cijfers, dat wil zeggen of de onderliggende jaarrekening inmiddels is voorzien van een accountantsverklaring en - wanneer dat het geval is wat de strekking van die verklaring is (goedkeurend, afkeurend, met beperking of met oordeelonthouding). Persberichten waarmee ondernemingen jaarcijfers naar buiten brengen, kunnen vaak als een dergelijke publicatie worden gezien. Uit onderzoek blijkt echter dat deze bepaling maar mondjesmaat wordt nageleefd (zie Vergoossen, 2004).

Internationaal zijn diverse initiatieven met betrekking tot alternatieve financiële prestatie-indicatoren ontplooid. In januari 2003 heeft de Amerikaanse beurstoezichthouder - de Securities and Exchange Commission (SEC) - in het kader van de Sarbanes-Oxley Act regels uitgevaardigd voor het gebruik van alterna- 
tieve financiële prestatie-indicatoren in rapportages ten behoeve van de SEC of in andere publicaties, waaronder persberichten. Deze regels zijn van kracht vanaf 28 maart 2003. Onder deze regelgeving is het verplicht om bij gebruik van alternatieve financiële prestatie-indicatoren een numerieke aansluiting te tonen met maatstaven in overeenstemming met GAAP. Voorts is het verplicht om in de financiële informatie de reden aan te geven van het gebruik van alternatieve financiële prestatie-indicatoren. Het is expliciet verboden om onjuiste of misleidende alternatieve financiële prestatie-indicatoren te tonen. Verder is het niet toegestaan om alternatieve financiële prestatieindicatoren met gelijke of grotere prominentie te presenteren ten opzichte van financiële prestatie-indicatoren in overeenstemming met GAAP.

De International Financial Reporting Standards (IFRS) bevatten geen modellen voor de winst- en verliesrekening, hetgeen het gebruik van alternatieve financiële prestatie-indicatoren in de hand werkt. De International Accounting Standards Board (IASB) spreekt momenteel echter wel over de rapportering van financiële prestaties van ondernemingen, maar dit beperkt zich tot de toepassing daarvan in de jaarrekening en is niet gericht op andere financiële publicaties zoals persberichten (zie project update Performance Reporting d.d. 25 oktober 2004).

De International Organization of Securities Commissions (IOSCO), het mondiale forum van toezichthouders op het effectenverkeer, bracht in 2002 een waarschuwing uit aan beleggers, waarvan de kern is dat zij zich moeten realiseren dat alternatieve financiële prestatie-indicatoren vaak grote kostenposten buiten beschouwing laten. IOSCO adviseert beleggers om alle alternatieve financiële prestatie-indicatoren in persberichten en andere publicaties te vergelijken met de resultaten in de jaarrekening ${ }^{4}$.

\section{Doel, reikwijdte en aanpak onderzoek}

Het onderzoek naar het gebruik van alternatieve financiële prestatie-indicatoren in persberichten is uitgevoerd tegen de achtergrond dat:

- bedrijven mogelijk kansen zien om gunstiger ogende resultaten in hun persberichten te tonen door het gebruik van alternatieve financiële prestatieindicatoren;

- bedrijven mogelijk de resultaten op basis van alternatieve financiële prestatie-indicatoren een prominentere plaats laten innemen dan prestatie-indicatoren in overeenstemming met (Nederlandse) GAAP;

- tussen de bedrijven onderling geen consistentie is in de gebruikte (winst)begrippen;
- besturen van ondernemingen zelf ook worstelen met de vraag welke alternatieve financiële prestatie-indicatoren het beste gehanteerd kunnen worden;

- de SEC in de Verenigde Staten in 2003 specifieke regelgeving heeft uitgevaardigd over het gebruik van alternatieve financiële prestatie-indicatoren.

Het doel van het onderzoek is om kennis op te doen met betrekking tot:

- het soort alternatieve financiële prestatie-indicatoren dat beursgenoteerde ondernemingen in hun persberichten gebruiken;

- de intensiteit van het gebruik van alternatieve financiële prestatie-indicatoren;

- de prominentie waarmee alternatieve financiële prestatie-indicatoren worden gebracht;

- de mate waarin ondernemingen alternatieve financiële prestatie-indicatoren laten vergezellen van de gedefinieerde financiële prestatie-indicatoren (reconciliatie);

- de mate waarin ondernemingen toelichting geven bij de alternatieve financiële prestatie-indicatoren;

- eventuele afwijkingen die ondernemingen opgenomen in de AEX-index vertonen in het gebruik van alternatieve financiële prestatie-indicatoren ten opzichte van andere beursgenoteerde ondernemingen;

- het consistent gebruik van alternatieve financiële prestatie-indicatoren door ondernemingen in de tijd gezien.

Het onderzoek richt zich in eerste instantie op de persberichten van ondernemingen met de volgende omschrijving:

- Nederlandse ondernemingen;

- met een aandelennotering aan Euronext Amsterdam (peildatum 17 mei 2003);

- niet zijnde vastgoedfondsen;

- die niet failliet, in surseance of anderszins inactief zijn.

Van deze 146 ondernemingen zijn de via internet beschikbare persberichten inzake de publicatie van de jaarcijfers 2002 onderzocht. De persberichten zijn beoordeeld ten aanzien van het gebruik van alternatieve financiële prestatie-indicatoren en - wanneer dat het geval is - of dit wordt toegelicht en of een aansluiting met financiële prestatie-indicatoren in overeenstemming met GAAP wordt weergegeven (reconciliatie). In het onderzoek is een nuancering aangebracht voor de mate van prominentie waarmee alternatieve financiële prestatie-indicatoren worden gebracht. Een getal is 'prominent' wanneer het in het oog springt, bijvoorbeeld doordat het in het begin van het persbericht staat, in een nadrukkelijke vormgeving (bijvoorbeeld groot of vet gedrukt) of een combinatie daarvan. Een 
onderneming kan via de prominente presentatie meer nadruk leggen op alternatieve financiële prestatieindicatoren. Op grond van deze prominent gebrachte informatie zouden lezers van persberichten een bepaald oordeel kunnen vormen dat afwijkt van een oordeel op basis van gedefinieerde (winst)begrippen. Ook is onderzocht of en in hoeverre ondernemingen opgenomen in de AEX-index in het gebruik van alternatieve financiële prestatie-indicatoren afwijken van andere beursgenoteerde ondernemingen.

In tweede instantie is een verdieping aangebracht door persberichten van ondernemingen opgenomen in de AEX-index door de tijd heen te onderzoeken, namelijk van het vierde kwartaal 2001 tot en met het vierde kwartaal 2003. De persberichten over de genoemde periode betreffen zowel de persberichten over de jaarcijfers, de halfjaarcijfers als - indien voorhanden - de kwartaalcijfers. Doel hiervan is om na te gaan of ondernemingen alternatieve financiële prestatie-indicatoren in de tijd consistent gebruiken.

Het onderzoek is beperkt tot financiële prestatie-indicatoren in de categorieën omzet, resultaat en winst per aandeel.

\section{Resultaten onderzoek}

Uit het onderzoek blijkt dat veel ondernemingen één of meer alternatieve financiële prestatie-indicatoren presenteren in hun persberichten. Ondernemingen lijken de behoefte te hebben om alternatieve financiële prestatie-indicatoren toe te passen die afwijken van prestatie-indicatoren in overeenstemming met GAAP. Het kan zijn dat een onderneming op deze wijze een beter beeld wil geven van haar financiële prestaties omdat - naar de mening van de onderneming - de financiële prestatie-indicatoren die in overeenstemming zijn met GAAP niet dat inzicht aan de gebruiker zouden verschaffen. Mogelijk is dat ingegeven doordat andere ondernemingen ook alternatieve financiële prestatie-indicatoren gebruiken en daardoor ondernemingen onderling beter vergeleken kunnen worden. Het komt echter ook voor dat ondernemingen één en dezelfde alternatieve financiële prestatieindicator anders definiëren, zodat de vergelijkbaarheid juist verslechtert.

Het blijkt dat de in het onderzoek betrokken ondernemingen een verscheidenheid aan termen gebruiken als alternatieve financiële prestatie-indicatoren. Behalve het wijdverspreide gebruik van EBIT, EBITA en EBITDA een greep hieruit (zie ook de appendix voor een uitgebreide lijst):

- omzet/EBITDA/bedrijfsresultaat/winst per aandeel voor bijzondere kosten en/of baten;

- nettowinst/winst per aandeel voor amortisatie van goodwill;

- genormaliseerde nettowinst/winst per aandeel;

- autonome omzet/autonoom resultaat;

- omzet/resultaat voor effect wisselkoersen;

- resultaat uit gewone bedrijfsuitoefening na belasting, voor afschrijving goodwill met aanpassing van de consolidatiekring voor verkochte deelnemingen;

- cash earnings.

Ondernemingen lichten doorgaans niet of nauwelijks toe wat zij onder de gehanteerde begrippen verstaan. Wel vullen ondernemingen persberichten geregeld aan met een balans en winst- en verliesrekening bij het persbericht, zodat geïnteresseerden zelf de gedefinieerde winstbegrippen kunnen opzoeken.

Hieronder volgen de resultaten uit het onderzoek naar intensiteit (5.1), prominentie (5.2), reconciliatie (5.3), en misleidend gebruik (5.4) van alternatieve financiële

Tabel 1. Intensiteit gebruik alternatieve financiële prestatie-indicatoren

Intensiteit

In het geheel geen gegevens

Alleen gedefinieerde (winst)begrippen

Eén alternatieve financiële prestatie-indicator

Twee alternatieve financiële prestatie-indicatoren

Drie alternatieve financiële prestatie-indicatoren

Vier alternatieve financiële prestatie-indicatoren
Omzet

n

(\%)

$22 \quad$ (15)

$102 \quad(70)$

$18 \quad(12$

$4 \quad(3)$

-

-

Totaal aantal ondernemingen

146

(100)

Resultaat

(\%)

(1)

(42)

(33)

(15)

(6)

(3)

$146 \quad(100)$
Winst per aandeel

n

(\%)

(36)

(30)

(30)

(3)

(1)

- - 
Tabel 2. Intensiteit gebruik AEX- respectievelijk overige ondernemingen

Intensiteit

Ondernemingen die alternatieve financiële

prestatie-indicatoren gebruiken

Ondernemingen die alleen gedefinieerde

winstbegrippen gebruiken

Totaal aantal ondernemingen

Peildatum 17 mei 2003.
AEX

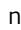

$24^{*}$
Overig

n
(8)

(92)

(100)

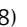

$\%)$ 
Tabel 4. Prominentie onderscheiden naar AEX- repectievelijk overige ondernemingen

\begin{tabular}{|c|c|c|c|c|c|c|}
\hline \multirow[t]{2}{*}{ Prominentie } & \multicolumn{2}{|c|}{ Omzet } & \multicolumn{2}{|c|}{ Resultaat } & \multicolumn{2}{|c|}{ Winst per aandeel } \\
\hline & $\mathrm{n}$ & $(\%)$ & $\mathrm{n}$ & $(\%)$ & $\mathrm{n}$ & $(\%)$ \\
\hline AEX-ondernemingen & 5 & (33) & 17 & (23) & 9 & $(25)$ \\
\hline Andere ondernemingen & 10 & $(67)$ & 57 & (77) & 27 & (75) \\
\hline \multicolumn{7}{|c|}{ Totaal prominent gebruik alternatieve } \\
\hline financiële prestatie-indicatoren & 15 & (100) & 74 & (100) & 36 & (100) \\
\hline
\end{tabular}

Tabel 5. Reconciliatie van alternatieve financiële prestatie-indicatoren

Reconciliatie

Geen reconciliatie alternatieve financiële

prestatie-indicatoren

Reconciliatie alternatieve financiële

prestatie-indicatoren

Totaal gebruik alternatieve financiële

\section{Omzet}

n

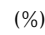

Resultaat n $\quad(\%)$

(12)

10

73

$21 \quad(95)$
(5)

5)

(100)

Winst per aandeel

n

(\%)

(47)

(53)

prestatie-indicatoren

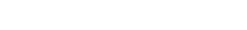

(100) 51

(100)

van de tekst van het persbericht voorkomen.

Uit tabel 3 blijkt dat ondernemingen alternatieve financiële prestatie-indicatoren doorgaans prominent brengen.

Tabel 4 bevat de prominent gebrachte alternatieve financiële prestatie-indicatoren, onderscheiden naar AEX-ondernemingen en overige ondernemingen.

Aangezien de persberichten van AEX-ondernemingen $16 \%$ van het totaal aantal onderzochte persberichten uitmaakt, geeft tabel 4 aan dat de AEX-ondernemingen alternatieve financiële prestatie-indicatoren met meer prominentie brengen dan niet-AEX-ondernemingen.

\subsection{Reconciliatie}

In het onderzoek komt naar voren dat in 35 gevallen (31 ondernemingen) geen reconciliatie van alternatieve financiële prestatie-indicatoren wordt gegeven (zie tabel 5).

Uit tabel 5 blijkt dat in de categorieën Omzet en Resultaat een aanzienlijk aantal ondernemingen zowel gedefinieerde als alternatieve financiële prestatie-indicatoren geeft. In de categorie Winst per aan- deel reconcilieert echter maar de helft van de ondernemingen.

Wanneer ondernemingen een winst- en verliesrekening als bijlage bij het persbericht geven, is dit door ons niet opgevat als een reconciliatie, deels omdat persberichten soms vele pagina's beslaan, deels omdat het in het onderzoek gaat om de persberichten zelf en niet om aanvullende informatie die doorgaans ook beschikbaar is.

In tabel 6 (p. 202) is onderscheid gemaakt naar AEXondernemingen en overige beursgenoteerde ondernemingen voor wat betreft de reconciliatie van alternatieve financiële prestatie-indicatoren presenteren. Op basis van de $\chi^{2}$-toets kan niet worden geconcludeerd dat AEX-ondernemingen significant vaker reconciliatie van alternatieve financiële prestatie-indicatoren achterwege laten dan andere ondernemingen ${ }^{7}$.

\subsection{Misleidend gebruik van alternatieve financiële prestatie-indicatoren}

In het onderzoek komt naar voren dat zeven ondernemingen gedefinieerde financiële prestatie-indicatoren vermelden, terwijl hierachter bij nader inzien 
Tabel 6. Reconciliatie onderscheiden naar AEX- respectievelijk overige ondernemingen

\begin{tabular}{|c|c|c|c|c|c|c|}
\hline \multirow[t]{2}{*}{ Reconciliatie } & \multicolumn{2}{|c|}{ AEX } & \multicolumn{2}{|c|}{ Overig } & \multicolumn{2}{|c|}{ Totaal } \\
\hline & $\mathrm{n}$ & $(\%)$ & $\mathrm{n}$ & $(\%)$ & $\mathrm{n}$ & $(\%)$ \\
\hline Geen reconciliatie alternatieve financiële prestatie-indicatoren & 10 & (50) & 21 & (31) & 31 & (36) \\
\hline Reconciliatie alternatieve financiële prestatie-indicatoren & 10 & (50) & 46 & (69) & 56 & (64) \\
\hline Totaal gebruik alternatieve financiële prestatie-indicatoren & 20 & (100) & 67 & (100) & 87 & (100) \\
\hline
\end{tabular}

Tabel 7. Misleidend gebruik van alternatieve financiële prestatie-indicatoren

Misleidend gebruik

AEX

$\mathrm{n}$

Alternatieve financiële prestatie-indicator gepresenteerd als

gedefinieerde financiële prestatie-indicator

Geen misleidend gebruik

Totaal gebruik alternatieve financiële prestatie-indicatoren
5

15

20
$(\%)$

(25)

(75)

(100)

\section{Overig}

$\mathrm{n}$

(\%)

Totaal

n

(\%)

(8)

(92)

(97)

80

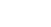

(100)

87

(100) alternatieve financiële prestatie-indicatoren blijken schuil te gaan. Een voorbeeld hiervan is de kop van een persbericht die vermeldt dat de nettowinst met een bepaald percentage is gestegen. Verderop in het persbericht blijkt dat het niet om de nettowinst gaat, maar om het resultaat voor bijzondere kosten. Dergelijke presentaties zijn in dit onderzoek gekwalificeerd als misleidend gebruik van alternatieve financiële prestatie-indicatoren.

In alle geconstateerde gevallen gaat het om resultaatverlagende posten die zijn geëlimineerd in de alternatieve financiële prestatie-indicatoren, namelijk:

- in één geval gaat het om het omzetgroeicijfer, dat bij nader inzien blijkt te gaan om een groeicijfer van de omzet op basis van constante wisselkoersen;

- in drie andere gevallen blijkt het genoemde winstcijfer een aantal bijzondere kostenposten buiten beschouwing te laten;

- in twee gevallen gaat het om het bedrijfsresultaat dat exclusief bijzondere kosten was opgenomen; en

- in één geval blijkt de winst per aandeel niet alle kosten te incorporeren.

Mogelijk is het vaker voorgekomen dat ondernemingen dergelijke misleidende berichten in de wereld hebben gebracht. Het onderzoek was hier echter niet specifiek op gericht, en deze bevindingen berusten dan ook op min of meer toevallige ontdekkingen.
Tabel 7 moet dan ook in dit licht worden gezien: het geconstateerde misleidende gebruik is een minimum en de verdeling over AEX-ondernemingen en overige ondernemingen zou bij een specifiek daarop gericht onderzoek anders kunnen uitvallen.

Tabel 7 laat zien dat vijf van de zeven geconstateerde misleidende presentaties van (winst)begrippen bij AEX-ondernemingen plaatsvinden. Hieruit kan worden afgeleid dat deze ondernemingen oververtegenwoordigd zijn bij het ten onrechte presenteren van alternatieve financiële prestatie-indicatoren als gedefinieerde (winst)begrippen. Dit wordt bevestigd door de $\chi^{2}$-toets die hier een significant verband laat zien'.

\subsection{Consistent gebruik van alternatieve financiële prestatie-indicatoren}

Zoals hiervoor gemeld, hebben wij met betrekking tot de beursgenoteerde ondernemingen opgenomen in de AEX-index niet alleen de persberichten inzake de jaarcijfers 2002 onderzocht. Om inzicht te krijgen in de mate waarin deze ondernemingen alternatieve financiële prestatie-indicatoren op consistente wijze gebruiken, zijn de persberichten inzake de jaar-, halfjaar- en kwartaalcijfers over de periode van het vierde kwartaal 2001 tot en met het vierde kwartaal 2003 onderzocht. Omdat in het onderzoek alleen Nederlandse ondernemingen zijn betrokken en de AEXindex één buitenlandse onderneming bevat, zijn 24 
ondernemingen in het onderzoek betrokken met in totaal 180 persberichten.

Het blijkt dat ten minste 15 ondernemingen (63\%) in de loop van genoemde periode hun alternatieve financiële prestatie-indicatoren hebben aangepast of nieuwe alternatieve financiële prestatie-indicatoren hebben geïntroduceerd. Het aantal van 15 moet worden gelezen als een minimum omdat ondernemingen niet altijd even transparant zijn over de betekenis van gebruikte alternatieve financiële prestatie-indicatoren. Naast het feit dat het gebruik van alternatieve financiële prestatie-indicatoren op zichzelf al de nodige vragen oproept omtrent de vergelijkbaarheid van financiële informatie tussen ondernemingen, wordt de volgtijdelijke vergelijkbaarheid van financiële informatie van individuele ondernemingen bemoeilijkt indien alternatieve financiële prestatie-indicatoren in de loop van de tijd worden aangepast. Dit geldt nog meer wanneer niet wordt toegelicht dat en waarom deze aanpassing heeft plaatsgevonden.

\section{Conclusies}

Uit onderzoek van 146 persberichten inzake de jaarcijfers over 2002 van Nederlandse beursgenoteerde ondernemingen blijkt dat alternatieve financiële prestatie-indicatoren veelvuldig worden gebruikt, veelal een prominente plaats hebben in het persbericht en dat ansluiting met de gedefinieerde (winst)begrippen regelmatig achterwege blijft. In het onderzoek komt naar voren dat zeven ondernemingen alternatieve financiële prestatie-indicatoren zelfs op een misleidende wijze gebruiken door ten onrechte gedefinieerde (winst)begrippen te gebruiken voor resultaten waarin posten met een negatieve invloed op het resultaat buiten beschouwing zijn gebleven.

Ondernemingen opgenomen in de AEX-index vertonen gedurende het vierde kwartaal 2001 tot en met het vierde kwartaal 2003 een weinig consistent gebruik van alternatieve financiële prestatie-indicatoren. Bovendien geven deze ondernemingen weinig toelichting op de gebruikte alternatieve financiële prestatie-indicatoren en de reden waarom zij deze informatie aan beleggers geven. De AEX-ondernemingen maken in hun persberichten met betrekking tot de jaarcijfers 2002 meer gebruik van alternatieve financiële prestatie-indicatoren dan andere ondernemingen. Ook zijn zij sterk oververtegenwoordigd bij de ondernemingen die in die persberichten een als misleidend te kwalificeren voorstelling van hun resultaten geven.

Omdat het gebruik van alternatieve financiële prestatie-indicatoren de transparantie op de financiële markten kan hinderen, hebben diverse partijen dit onderwerp aan de kaak gesteld. IOSCO heeft beleggers gewaarschuwd voor alternatieve financiële prestatie-indicatoren en in de Verenigde Staten heeft de SEC gereageerd met regelgeving. In Nederland heeft het Koninklijk Nederlands Instituut van Registeraccountants (NIVRA) zijn leden opgeroepen om alternatieve financiële prestatie-indicatoren in de jaarrekening onder de loep te nemen. De AFM heeft aanbevelingen opgesteld voor het gebruik van alternatieve financiële prestatie-indicatoren in de financiële verslaggeving en daarnaast beursgenoteerde ondernemingen die alternatieve financiële prestatie-indicatoren op een niet-gewenste wijze gebruiken, aangeschreven en gemaand tot een betere presentatie van financiële resultaten.

Dit jaar gaan de beursgenoteerde ondernemingen in de Europese Unie over op de IFRS. De Europese Commissie heeft angekondigd dat de Europese modellen voor de winst- en verliesrekening, zoals in Nederland vastgelegd in het BMJ, dan niet meer gelden voor de geconsolideerde jaarrekening. Omdat de IFRS geen vast model voorschrijven, bestaat het risico dat ongewenst gebruik van alternatieve financiële prestatie-indicatoren toeneemt. Omdat persberichten een breed lezerspubliek hebben, frequenter verschijnen (kwartaal- en halfjaarcijfers) en - als het de jaarcijfers betreft - enige tijd voorafgaand aan de jaarrekening zelf verschijnen, zouden beleggers uit deze niet-gereguleerde persberichten in voorkomende gevallen verkeerde conclusies over de behaalde resultaten kunnen trekken. Dat kan worden voorkomen door Europese regelgeving over definitie en gebruik van alternatieve financiële prestatie-indicatoren in de financiële verslaggeving. Diverse partijen kunnen daarbij actie ondernemen.

Ten eerste heeft de IASB een project onder handen voor de vorm waarin de winst- en verliesrekening wordt gepresenteerd. In dit project is de definiëring van alternatieve financiële prestatie-indicatoren op zijn plaats. Dit project is echter bijzonder omvangrijk en het zal nog wel enige tijd duren voordat een definitieve standaard hierover het licht ziet.

Ten tweede kan de Europese Commissie haar mening herzien en de vastgelegde modellen voor de winst- en verliesrekening alsnog van toepassing verklaren, in elk geval tot het moment dat de IASB een model voor de winst- en verliesrekening heeft ontwikkeld.

Ten derde kan het Committee of European Securities Regulators (CESR), het samenwerkingsverband van Europese beurstoezichthouders, in navolging van de SEC een aanbeveling uitbrengen waarin financiële 
termen worden gedefinieerd en waarin het gebruik van alternatieve financiële prestatie-indicatoren enigszins aan banden wordt gelegd. Overigens wordt een dergelijke aanbeveling op korte termijn verwacht. In Nederland hebben ondernemingen uit hoofde van artikel 2:395 lid 2 BW de plicht om duidelijkheid te verschaffen omtrent de status van de cijfers indien het persbericht een beknopte jaarrekening of een gedeelte van de jaarrekening bevat, dat wil zeggen of de onderliggende jaarrekening inmiddels is gecontroleerd en, zo ja, wat de strekking van de accountantsverklaring is. Accountants zouden daarom van hun beursgenoteerde opdrachtgevers moeten eisen dat zij deze persberichten onder ogen krijgen voordat die worden gepubliceerd. Zij moeten dan vaststellen of de persberichten geen strijdigheden met de onderliggende jaarrekening bevatten. Het NIVRA zou voorstellen kunnen doen hoe een dergelijke beoordeling vorm zou moeten worden gegeven en hoe hierover zou moeten worden gecommuniceerd.

Zolang het gebruik van alternatieve financiële prestatie-indicatoren niet adequaat is geregeld, doen beleggers er goed aan de waarschuwing van IOSCO ter harte te nemen en de nodige voorzichtigheid te betrachten bij het nemen van beslissingen op basis van in persberichten gepresenteerde resultaten.

\section{Literatuur}

Autoriteit Financiële Markten, (2004), Non-GAAP earnings measures, persbericht 17 februari, www.afm.nl.

Autorité des Marches Financiers, (2002), Mise en garde sur les indicateurs de résultats non conformes aux principes comptables généralement reconnus (GAAP), 24 juni, www.amf-france.org.

Deloitte \& Touche, (2003), Conditions for Use of Non-GAAP Financial Measures, juli.

Ernst \& Young, (2004), Meerderheid AEX-ondernemingen maakt gebruik van alternatieve prestatie-indicatoren in persberichten, persbericht 21 januari.

Hendriks, J.J. en R.G.A. Vergoossen, (2004), Ebitda taboe in persberichten, in: Het Financieele Dagblad, 23 februari.

Hooghiemstra, R.B.H. en L.G. van der Tas, (2003), Rapportering over financial performance, in: J.B. Backhuijs, R.G. Bosman en C.D. Knoops, Het jaar 2002 verslagen. Onderzoek jaarverslaggeving Nederlandse ondernemingen, Kluwer/Koninklijk NIVRA.

Hooghiemstra R.B.H. en L.G. van der Tas, (2004), Informatieverschaffing over prestatie-indicatoren, in: J.B. Backhuijs, R.G. Bosman en C. Camfferman, Het jaar 2003 verslagen. Onderzoek jaarverslaggeving Nederlandse ondernemingen, Kluwer/Koninklijk NIVRA, 2004.

International Organization of Securities Commissions, (2002), Cautionary Statement Regarding non-GAAP results measures, 19 mei.

Securities and Exchange Commission, (2003), Conditions for Use of NonGAAP Financial Measures, Release No. 33-8176, effective as from March 28, 2003.

Securities and Exchange Commission, (2003), Summary by the Division of
Corporation Finance of Significant Issues Addressed in the Review of the Periodic Reports of the Fortune 500 Companies, 27 februari.

Raad voor de Jaarverslaggeving, Richtlijnen voor de jaarverslaggeving, jaareditie 2004, Richtlijn 270, De winst- en verliesrekening, paragraaf 709.

Vergoossen R.G.A, (2004), Strenger toezicht op persberichten, in: Het Financieele Dagblad, 6 juli.

\section{Noten}

1 Zie Hooghiemstra en Van der Tas $(2003,2004)$ voor onderzoeken naar het gebruik van alternatieve financiële prestatie-indicatoren in jaarrekeningen.

2 De AFM onderzocht de persberichten van de Nederlandse beursgenoteerde ondernemingen inzake de publicatie van de jaarcijfers 2002, terwijl het onderzoek van Ernst \& Young Accountants was gericht op de persberichten van de ondernemingen opgenomen in de AEX-index inzake de jaar-, halfjaar- en kwartaalcijfers over een periode van ruim twee jaar (laatste kwartaal 2001 tot en met laatste kwartaal 2003). Aan het onderzoek hebben de volgende personen hun medewerking verleend: Janine Hogendoorn en Michal Bakker-Levy van de AFM en Joost Hendriks, Jos Hesselink en Bram Tijsseling van Ernst \& Young Accountants.

3 Zie persbericht 'Non-GAAP earnings measures' van 17 februari 2004, www.afm.nl.

4 International Organization of Securities Commissions, 'Cautionary Statement Regarding non-GAAP results measures', d.d. 19 mei 2002, www.iosco.org.

5 Door middel van de $X^{2}$-toets wordt de variantie berekend van het verschil tussen de geconstateerde uitkomst en de verwachte waarde van de uitkomst.

$6 \mathrm{X}^{2}$-toets levert een waarde van 6,72 terwijl de grenswaarde 6,64 is bij een betrouwbaarheid van $99 \%$.

$7 \mathrm{X}^{2}$-toets levert een waarde van 2,34, terwijl de grenswaarde 3,84 is bij een betrouwbaarheid van $95 \%$.

$8 \mathrm{X}^{2}$-toets levert een waarde van 10,09 terwijl de grenswaarde 6,64 is bij een betrouwbaarheid van $99 \%$.

9 Par. 4.2 of the Comments concerning certain Articles of the Regulation (EC) No 1606/2002 of the European Parliament and of the Council of 19 July 2002 on the application of international accounting standards and the Fourth Council Directive 78/660/EEC of 25 July 1978 and the Seventh Council Directive 83/349/EEC of 13 June 1983 on accounting, November 2003, zie www.europa.eu.int/comm/internal_market/ accounting/ias_en.htm\#comments 